\title{
Maximizing Opportunities and Minimizing Risks for Children Online: The Role of Digital Skills in Emerging Strategies of Parental Mediation
}

\author{
Sonia Livingstone ${ }^{1}$, Kjartan Ólafsson ${ }^{2}$, Ellen J. Helsper ${ }^{1}$, \\ Francisco Lupiáñez-Villanueva ${ }^{3}$, Giuseppe A. Veltrii ${ }^{4}$ \& Frans Folkvord ${ }^{3,5}$ \\ 1 Department of Media and Communications, London School of Economics and Political Science, London \\ WC2A 2AE, UK \\ 2 Department of Social Sciences, University of Akureyri, IS-600 Akureyri, Iceland \\ 3 Estudis de Ciències de la Informació i de la Comunicació, Universitat Oberta de Catalunya, Barcelona 08018, \\ Spain \\ 4 School of Media, Communication and Sociology, University of Leicester, LE1 7JR Leicester, UK \\ 5 Behavioural Science Institute, Radboud University Nijmegen, 6526 GD Nijmegen, Netherlands
}

\begin{abstract}
As Internet use becomes widespread at home, parents are trying to maximize their children's online opportunities while also minimizing online risks. We surveyed parents of 6to 14-year-olds in 8 European countries $(N=6,400)$. A factor analysis revealed 2 parental mediation strategies. Enabling mediation is associated with increased online opportunities but also risks. This strategy incorporates safety efforts, responds to child agency, and is employed when the parent or child is relatively digitally skilled, so may not support harm. Restrictive mediation is associated with fewer online risks but at the cost of opportunities, reflecting policy advice that regards media use as primarily problematic. It is favored when parent or child digital skills are lower, potentially keeping vulnerable children safe yet undermining their digital inclusion.
\end{abstract}

Keywords: Parental Mediation, Internet, Online Risks, Online Opportunities, Child Agency, Digital Skills, Policy Guidance, Parental Style.

doi:10.1111/jcom.12277

In today's media-rich, technologically innovative environment, society relies heavily on parents for ensuring children are prepared to meet the changing expectations of education and work, while also kept safe from a host of online risks. On the one hand, the more parents can maximize children's online opportunities and minimize the risks, the less burden is placed on government, regulators, or educators to shape

Corresponding author: Sonia Livingstone; e-mail: S.Livingstone@lse.ac.uk 
individual engagement with fast-changing global media in the risk society (Beck, 1992; Jessop, 2000). On the other hand, in the high-pressure "democratic family" (Giddens, 1991; Ochs \& Kemer-Sadlik, 2013), parents are struggling to meet children's demands and needs in relation to increasingly complex digital media (Clark, 2011; Ofcom, 2016). One emerging resolution is to update policy guidance and parental support so as to recognize parental investment in digital technologies at home and empower them to tailor their domestic media environment to fit the needs of each child as well as their own values (Blum-Ross \& Livingstone, 2016; O’Neill, Staksrud, \& McLaughlin, 2013).

Educators, regulators, parent advisors, and child welfare professionals often turn to research to inform parental awareness campaigns or determine what may be expected of parents. But this advice has been heavily influenced by the legacy of dominant mass media, where media exposure has primarily been regarded as potentially harmful. Indeed, for many years, research has predominantly examined parental efforts to restrict or reduce media exposure or mitigate its negative effects by enhancing children's critical media literacy, and policy advice has followed suit. While protection remains important, such advice is insufficient to meet growing expectations of children's digital media use in relation to learning, employment, communication, and participation (Garmendia, Garitaonandia, Martinez, \& Casado, 2012; Livingstone, 2013). Although recently there are growing signs of acceptance that there can be benefits from media use, albeit still within a highly protectionist agenda (Chassiakos, Radesky, Christakis, Moreno, \& Cross, 2016), it remains to be understood how parents can safely optimize use of the digital media that many are investing in at home. This article analyzes a large-scale survey of parents to see if they are close to finding the "holy grail" of simultaneously optimizing the online opportunities for children while minimizing online risks.

\section{Parental mediation of children's Internet use}

In relation to television, three strategies are commonly identified: active (or evaluative), restrictive, and co-use. Restrictive mediation of children's television exposure is most effective in reducing exposure (Nathanson, 1999; Valkenburg, Krcmar, Peeters, \& Marseille, 1999), with weaker evidence for the benefits of active mediation (Nathanson, 2015) or co-use (Connell, Lauricella, \& Wartella, 2015; Troseth, Russo, \& Strouse, 2016). In examining parental mediation strategies for children's Internet use, researchers began with the strategies already identified for television use. In a 2005 survey of British 9- to 19-year-olds, Livingstone and Helsper (2008) found that restrictive mediation (rules, time limits, and bans on particular activities or contents) was commonly used, as were technical controls (parental tools and filters of various kinds), but that the distinction between active mediation (talking about and explaining the media) and co-use (sharing the activity) was no longer applicable. They argued that while parents and children may watch television together without conversation, the close proximity, focus on a shared screen, and active decisions (where to click, 
what to select) required by Internet use invites social interaction, blurring co-use and active mediation (see also Garmendia et al., 2012; Troseth et al., 2016; Valkenburg, Piotrowski, Hermanns, \& de Leeuw, 2013). Extending this approach across 25 European countries, the EU Kids Online network identified five distinct strategies for 9to 16-year-olds (Livingstone, Haddon, Görzig, \& Ólafsson, 2011): active mediation of Internet use (actively discussing and/or sharing the activity); active mediation of Internet safety; restrictive mediation; technical controls; and monitoring (checking on the child's online activities after use). These have been adopted by Chang et al.'s (2015) survey of junior high school students and Nikken and Schols' (2015) survey of the parents of under-8s, among others.

However, it is not only that parents are trying out a wider range of parental mediation strategies in their efforts to increase opportunities while also reducing risks, but also that other factors shape their strategies over and above personal preferences and values. Particularly, digital media are increasingly complex, and research shows that personal levels of digital skill are decisive in whether people are able to take full advantage of the opportunities that the Internet offers while avoiding associated harms (Hargittai, 2002; Helsper, 2012; Litt, 2013). While research to define and measure digital skills continues, it is clear that the concept includes more than functional skills to encompass critical information literacy, social/communicative and content-creation skills, and others (van Deursen, Helsper, \& Eynon, 2015). This suggests that the digital skills of both parents and children will matter more in mediating children's Internet use than television viewing. Some evidence already shows that parental mediation of the Internet is practiced more by educated and/or digitally skilled parents, and by parents of younger (and presumably less skilled) children (see Clark, 2011; Nikken \& Schols, 2015; Pasquier, Simões, \& Kredens, 2012; Shin \& Huh, 2011). In terms of mediation strategies, less educated and less digitally skilled parents of 9- to 16-year-olds undertake more restrictive and less active mediation (Garmendia et al., 2012); they also set more inconsistent rules and prefer technical restrictions (Nikken \& Schols, 2015).

Insofar as children are often enthusiastic and skilled adopters of digital media, both researchers and parents are recognizing that their role in relation to parental mediation is changing - not only the object of media effects, and so the focus of top-down parental prescriptions but also agents making constructive choices in a mediated world (Troseth et al., 2016; Valkenburg et al., 2013). This calls for the attention to child-initiated activities within the repertoire of Internet mediation strategies, as children turn to parents for shared experience and support (Clark, 2011; Shin, 2013). Thus McDevitt and Chaffee (2002) write about "trickle-up influence," Valcke, Bonte, de Wever, and Rots (2010) explore "reverse socialization," and van den Bulck, Custers, and Nelissen (2016) propose the "child effect" (see also Spink, Danby, Mallan, \& Butler, 2010). To theorize this, researchers draw on Vygotskian sociocultural theory of child development (see, e.g., Clark, 2011; Wartella et al., 2016) or, relatedly, family systems theory (McDevitt \& Chaffee, 2002; Rudi, Walkner, \& Dworkin, 2014) to locate parental mediation within wider family dynamics. 
Although the family is undergoing changes (Giddens, 1991), gender relations are slower to change; research shows that, for the Internet as with television, girls tend to be monitored and restricted more than boys, while mothers tend to play a more supportive parenting role and are more communicative than fathers (Eastin, Greenberg, \& Hofschire, 2006; Kirwil, 2009; Valcke et al., 2010).

\section{Consequences of parental mediation of children's Internet use}

Although most research on parental mediation uses correlational survey methods, able to hypothesize but not establish causal relations, it is worth noting the observed associations between parental mediation and children's experiences of online risks and, to a lesser degree, opportunities. Chang et al.'s (2015) survey of Taiwanese adolescents found that restrictive parental mediation helped in reducing Internet addiction and cyberbullying, while Khurana, Bleakley, Jordan, and Romer's (2015) U.S. survey of 12- to 17-year-olds found both parental monitoring and restrictions reduced online risks such as being cyberbullied (see also Mesch, 2009). In Lau and Yuen's (2013) review, some studies found restrictive strategies associated with reduced child online risk, but others found parental mediation generally ineffective (e.g., Leung \& Lee, 2012). Since such strategies are presumably motivated by the parental desire to reduce online risk, parental mediation may be associated with parents' perception of risk. This is commonly hypothesized, given the considerable public attention paid to online risks (Staksrud, 2013), but to our knowledge this has not been examined in relation to parental mediation of the Internet (although in other domains, parental risk perception has been linked to parents' own risk behavior and their efforts to protect their children; see, for example, Rosen \& Kostjukovsky, 2015, on smoking at home).

In terms of online opportunities, Troseth et al. (2016) review evidence that active mediation can facilitate child learning (see also Guernsey, Levine, Chiong, \& Severns, 2014), although Nathanson (2015) cautions that active mediation has been linked to worse outcomes for children. However, most research considers only risk outcomes without considering the effect of parental mediation on children's online opportunities (e.g., Vaala \& Bleakley, 2015). Parental emphasis on risks can itself be problematic for opportunities, since parental restrictions are correlated not only with lower online risk, but also with lower online opportunities (Garmendia et al., 2012; Mascheroni, Murru, Aristodemou, \& Laouris, 2013).

Must parents choose between restrictions that bring safety at the cost of online opportunities, and active mediation that facilities opportunities but also risks? Valkenburg et al. (2013, p. 461) advocate combining restrictive and active approaches, because "parents who enforce rules may be more successful when they stimulate their children's autonomy, that is, by taking their child's perspective seriously." Relatedly, drawing on Baumrind's (1991) classification of parenting styles, Rosen, Cheever, and Carrier (2008) found that authoritative (broadly, restrictive plus active), followed by authoritarian (just restrictive) strategies were associated with the fewest online risks. However, few studies have sought to grasp the combined consequences of particular parental mediation strategies for online risks and opportunities. 
To benefit from a large, multicountry survey of parents designed by the authors (Lupiáñez-Villanueva et al., 2016), this article builds on and extends prior research as follows. RQ1 tests the validity of the five strategies identified by EU Kids Online in 2010 (Livingstone et al., 2011), to see whether an underlying, simpler factor structure can be identified. This would facilitate research on the antecedents and consequences of parental mediation strategies and, thereby, the production of clear policy advice for parents. Recognizing how children themselves often take the lead in exploring online opportunities, we added to existing strategies a set of new items to examine child-initiated requests for parental support, informed by the literature reviewed above, to complement established parent-led measures (Dürager \& Sonck, 2014). To understand the antecedents of parental mediation, RQ2 recognizes that both parent and child digital skill could play a role, improving on previous measures of digital skill by adopting the multidimensional measure developed by van Deursen et al. (2015); we also include consideration of parental risk perception, as discussed above. Most important, RQ3 advances prior research by examining the consequences of parental mediation for the balance between the opportunities children take up on the Internet and the risks they encounter.

\section{Sample and data collection}

The target population was citizens aged 25-65, with children aged 6-14 living in their household and under their responsibility or care. The survey was conducted by computer-assisted web interviews (CAWI) using online panels in France, Germany, the Netherlands, Spain, Poland, Italy, Sweden, and the United Kingdom, with 800 interviews per country (total $N=6,400$ ). Quota sampling was used with random sampling within age quotas $(25-34,35-49$, and 50-64) to ensure a representative sample. Participants were paid after completing a number of surveys, with incentives in the form of gift cards, lotteries, or bank transfer. The survey followed European Society for Opinion and Marketing Research (2015) ethical guidelines, with ethical authorization provided by the London School of Economics' (LSE) Research Ethics Committee in all eight countries.

We sent an online invitation to participate in the survey to 77,381 individuals, resulting in 57,585 nonresponses. Of the 19,796 responses received, 5,420 were screened out, 2,130 were out of quota, 4,896 timed out, and 950 were rejected for reasons of quality control. The average interview length was 23 minutes. The data were collected between 26 February to 24 March 2015 . Sampling error was $\pm 1.25 \%$ for overall data and $\pm 3.54 \%$ for country-specific data. A maximum indeterminate probability $(p=q=50)$ for a confidence level of $95.5 \%$ applies to each reference population.

\section{Measures}

The survey was primarily intended to explore parental beliefs, concerns, and actions in relation to the commercial environment online, as part of a larger multimethod 
study (Lupiáñez-Villanueva et al., 2016). In the present article, we focus on the subset of measures relating to parent and child online skills, risks and opportunities, and parental mediation.

Child-related variables included age (mean 10.54 years, SD 2.61, range 6-14) and gender ( $46 \%$ girls). We measured digital skills on an agreement scale $(5=$ very true of my child to $1=$ not at all true of my child) for operational skills (five items), information/browsing skills (five items), social skills (five items), creative skills (five items), and mobile skills (four items) (adapted from van Deursen et al., 2015). ${ }^{1}$ Online opportunities were measured with the question, "how often does your child perform the following Internet activities?” [randomized presentation]; with frequency measured on a scale from $5=$ every day or almost every day to $1=$ never for each of 17 activities (e.g., "use the Internet for school work," "watch video clips," "download music or films") (from Livingstone et al., 2011). To measure online risks, the survey asked parents whether, as far as they were aware, their child had encountered each of 10 risks (e.g., seeing images with explicit violence, being treated in a hurtful or nasty way) in the past year $(y e s=1, n o=0$ ) (from Livingstone et al., 2011, with an additional item on the risk of being exposed to hidden advertisements). Both opportunities and risks scores were standardized.

Parent-related variables included age (mean 42.2 years, SD 7.44, range 25-64) and gender (51\% mothers). Education was measured using the ISCED classification with eight levels (UNESCO, 2006) and recoded as $0=$ has not completed a university degree and $1=$ has completed a university degree (35\% of the sample). The same digital skills items were measured as for their child (with the agreement scale: $5=$ very true of me to $1=$ not at all true of me). ${ }^{2}$ For parental mediation, we asked about five items for active mediation of Internet use (scale from $4=$ always to $0=$ never), eight items for active mediation of Internet safety $(5=$ always to $1=$ never $), 17$ items for parental restrictions $(0=$ can do this anytime, $1=$ can only do this with my permission or supervision, $2=$ can never do this), nine items for parental technical controls (yes $=1, n o=0)$, and six items for parental monitoring $(4=$ always to $0=$ never $)$ (from Livingstone et al., 2011). Based on growing recognition in the literature of children's agency in parental mediation interactions, we also included five items for child-initiated support (yes $=1, n o=0$ ). Last, for parental risk perception, for each of the 10 online risks, we multiplied a measure of how harmful it could be to the child $(1=$ not harmful at all to $7=$ very harmful $)$ and how likely it is to happen $(1=$ not likely at all to $7=$ very likely) (see Slovic, 2004). The combined score across risks was standardized.

\section{Scale construction for parental mediation}

Single scales were calculated for each of digital skills, online opportunities, and online risks by summing the contributing items. The resultant scales were normally distributed with means around the midpoints of the scales. The main focus of this article is the analysis of parental mediation measures. Based on prior scale testing across 
Europe (Dürager \& Sonck, 2014), items were combined to form scales ranging from 0 to 5 , as shown in Table 1.

\section{Results}

\section{RQ1: How do parent-led and child-led strategies shape parental mediation} of children's Internet use?

The internal consistency of the five scales (active mediation, safety mediation, restrictions, monitoring, and use of technical controls) developed by EU Kids Online is supported by the present survey data, with Cronbach's alpha ${ }^{3}$ levels ranging from 0.79 to 0.94 (see Table 1). The scale for child-initiated support, developed for the present survey, achieved an alpha of 0.67; this was considered just sufficient, though not strong, given that no established measure exists for a concept of growing theoretical value. ${ }^{4}$

From the mean scores, it can be seen that parents most favor active safety mediation, along with responsiveness to child-initiated support. Active mediation is favored next, with use of monitoring, restrictions, and technical controls all less popular. The correlation matrix in Table 2 shows these to be positively intercorrelated, suggesting that the more parents do one strategy, the more they do the others, with the exception of the restrictions scale, which is little correlated with most strategies except it is moderately positively correlated with active mediation of Internet use and negatively correlated with child-initiated support.

The correlation matrix suggests a possible factorization based on positive correlations among most variables but a markedly different pattern for parental restrictions. ${ }^{5}$ A factor analysis using principal components analysis and varimax rotation found a solution in which the first two factors accounted for $65 \%$ of the variance in the data $^{6}$ (see Table 3). We labeled factor 1 "enabling mediation" (with active mediation of Internet use, active mediation of Internet safety, technical controls, and parental monitoring all loading highly) and factor 2 "restrictive mediation" (characterized by a positive loading for restrictive mediation). Child-initiated support loaded positively on the "enabling mediation" and negatively on "restrictive mediation" factors. Two composite scales were constructed by summing the scores for the items on the component scales. On the basis of its positive loading and the relevant literature on family dynamics, we decided to include child-initiated support in calculating the enabling mediation scale, along with the above-listed high-loading items. It should be borne in mind, however, that child-initiated support is negatively related to the restrictive mediation factor. For enabling mediation, the mean was 3.00 (range $0-5, S D=0.96$ ) and for restrictive mediation, it was 2.47 (range $0-5, S D=1.35$ ).

\section{RQ2: What is the role of digital skills and risk perception in favoring enabling and restrictive mediation strategies?}

In regression analyses to identify which factors explained parental mediation preferences, we first entered child-related variables (age, gender, digital skills), then parent-related variables (age, gender, education, digital skills, and risk perception), and last, country (see Table 4). 
Table 1 Parental Mediation Strategies

When your child uses the Internet, do you ... (range 0-4)

Mean

$S D$

Talk to your child about what he/she does on the Internet?

0.85

Encourage your child to explore and learn things on the Internet?

2.89

0.97

Sit with your child while he/she uses the Internet?

2.38

0.95

Stay nearby when your child uses the Internet?

2.32

1.01

Do shared activities together with your child on the Internet?

2.72

0.91

Total: Active mediation of Internet use (alpha $=0.79$, range $0-5$ )

2.35

0.86

Has your child ever ... (range $0-1$ )

3.17

SD

Initiated a discussion with you about what she/he does on the

Mean

Internet?

Told you about things she/he finds disturbing on the Internet?

0.82

Asked for your advice on how she/he should act online?

0.56

Asked for products and/or services that she/he has seen

0.61

0.66 advertisements for online?

Ask for your help concerning a situation on the Internet that

she/he cannot handle?

Total: Child-initiated support (alpha $=0.67$, range $0-5$ )

3.33

How often do you do any of these things with your child? (range 0-4)

Help him/her when something is difficult to do or to find on the Internet

Suggest ways to use the Internet safely

Explain why some websites are appropriate or inappropriate

Help him/her when something has bothered him/her on the

Internet

Talk to him/her about what to do if something on the Internet

2.72 bothered him/her

Explain that online games may contain hidden advertising aimed at making children want to have new products

Explain that online games, even if downloaded without cost, may require in-app purchases in order to progress faster in the game or to access the full features of the game

Talk to him/her about the commercial activities they are exposed to online

Total: Active mediation of Internet safety (alpha $=0.93$, range $0-5$ )

Do you (or your partner/other carer) make use of any of the following... (range $0-1)$

Parental controls or other means of blocking or filtering some types of website

Parental controls or other means of keeping track of the websites or apps your child visits

Rules about how long or when your child is allowed to go online ${ }^{a}$

A service or contract that limits the time your child spends on the Internet

Software to prevent spam or junk mail/viruses

Parental controls that filter the apps your child can download 
Table 1 Continued

Parental controls that alert you when your child wants to buy 0.41 content (in-app purchase)

Software that limits the people your child can be in touch with (through voice calls and SMS/text/MMS)

Ad blocking software

Total: Technical controls (alpha $=0.84$, range $0-5$ )

2.54

When your child uses the Internet, how often do you (or your

Mean partner/other carer) check the following things afterwards? (range $0-4)$

Which websites he/she visited

Which friends or contacts he/she adds to his/her social networking profile/instant messaging service

The messages in his/her email or instant messaging account

His/her profile on a social networking or online community

The apps he/she downloaded

The in-app purchases he/she made

Total: Parental monitoring (alpha $=0.92$, range $0-5$ )

For each of these actions, please indicate if you CURRENTLY let

$\begin{array}{ll}2.58 & 1.52 \\ \text { Mean } & \text { SD }\end{array}$
your child perform them whenever she/he wants, or let her/him perform them but only with your permission or supervision, or you never let her/him perform them (range 0-2)

Use the Internet for school work

Watch video clips (e.g., on YouTube)

Download music or films

Read/watch news online

Visit a social networking profile

Visit a chat room

Use instant messaging

Play games with other people online

Spend time in a virtual world (e.g., Habbo, Club Penguin,

Put (or post) photos, videos or music online to share with others

$\begin{array}{ll}1.3 & 0.74\end{array}$

(including social networking or instant messaging)

Put (or post) a message on a website

Write a blog or online diary

$1.1 \quad 0.81$

Participate in a site concerned with good causes (e.g., campaigns,

$1.4 \quad 0.78$
charity)

1.20 .76

Use a file sharing site

Download games

Base: All parents $(N=6,400)$.

"This item is classified under "technical controls" because it correlates better with other technical controls items than with restrictions; note that the alpha for technical controls was not improved by omitting it, nor was the alpha for restrictions improved by adding it. 
Table 2 Correlations Among Parental Mediation Strategies

\begin{tabular}{|c|c|c|c|c|c|c|}
\hline & $\begin{array}{c}\text { Active } \\
\text { Mediation } \\
\text { of Use }\end{array}$ & $\begin{array}{l}\text { Child-initiated } \\
\text { Support }\end{array}$ & $\begin{array}{c}\text { Active } \\
\text { Mediation } \\
\text { of Safety }\end{array}$ & $\begin{array}{l}\text { Technical } \\
\text { Controls }\end{array}$ & $\begin{array}{c}\text { Parental } \\
\text { Monitoring }\end{array}$ & $\begin{array}{c}\text { Parental } \\
\text { Restrictions }\end{array}$ \\
\hline $\begin{array}{l}\text { Active } \\
\text { mediation of } \\
\text { Internet use }\end{array}$ & 1.00 & 0.30 & 0.51 & 0.36 & 0.48 & 0.26 \\
\hline $\begin{array}{l}\text { Child-initiated } \\
\text { support }\end{array}$ & & 1.00 & 0.45 & 0.25 & 0.35 & -0.22 \\
\hline $\begin{array}{l}\text { Active } \\
\text { mediation of } \\
\text { Internet } \\
\text { safety }\end{array}$ & & & 1.00 & 0.37 & 0.53 & -0.06 \\
\hline $\begin{array}{l}\text { Technical } \\
\text { controls }\end{array}$ & & & & 1.00 & 0.47 & 0.08 \\
\hline $\begin{array}{l}\text { Parental } \\
\quad \text { monitoring }\end{array}$ & & & & & 1.00 & $(0.01)$ \\
\hline $\begin{array}{l}\text { Parental } \\
\quad \text { restrictions }\end{array}$ & & & & & & 1.00 \\
\hline
\end{tabular}

Notes: Pearson's correlation coefficient, with number of respondents between 6,337 and 6,400. The number in brackets is not statistically significant at the 0.05 level.

Table 3 Factor Analysis of Parental Mediation Strategies

\begin{tabular}{lcc}
\hline & Enabling Mediation & Restrictive Mediation \\
\hline Active mediation of Internet use & 0.77 & 0.28 \\
Child-initiated support & 0.57 & -0.54 \\
Active mediation of Internet safety & 0.78 & -0.22 \\
Technical controls & 0.68 & 0.07 \\
Parental monitoring & 0.79 & -0.07 \\
Parental restrictions & 0.14 & 0.91 \\
\hline
\end{tabular}

The results show that parents do more enabling mediation for younger, more digitally skilled children. They also do more if they themselves are younger, female, or more digitally skilled. Parental risk perception matters too: Those who judge the online risk for their child to be greater undertake more enabling mediation. Country makes as big a difference as demographic variables, with more enabling in Spain and Italy, and less in Sweden and the Netherlands, compared to the United Kingdom, which is more or less in the middle. Much variance remains unexplained, however, in these models.

For restrictive mediation, the model explains over half of the variance, with child demographics mattering most. Parents are more restrictive, and less responsive to 
Table 4 Linear Regression Models Showing Unstandardized Slope Coefficients for Enabling and Restrictive Strategies of Parental Mediation

\begin{tabular}{|c|c|c|c|c|c|c|}
\hline \multirow[b]{2}{*}{ (Constant) } & \multicolumn{3}{|c|}{ Enabling Mediation $(0-5)$} & \multicolumn{3}{|c|}{ Restrictive Mediation $(0-5)$} \\
\hline & 1.96 & 1.46 & 1.37 & 4.64 & 4.39 & 4.40 \\
\hline Model & I & II & III & I & II & III \\
\hline Age & -0.07 & -0.05 & -0.06 & -0.14 & -0.15 & -0.15 \\
\hline Gender (girls $=1$ ) & $(-0.04)$ & $(-0.04)$ & $(-0.03)$ & 0.07 & -0.05 & $(-0.05)$ \\
\hline Skills $(0-5)$ & 0.33 & 0.30 & 0.30 & -0.70 & -0.71 & -0.70 \\
\hline Age of parent & & -0.01 & -0.01 & & 0.01 & 0.01 \\
\hline Gender $($ mothers $=1)$ & & 0.06 & 0.07 & & 0.29 & 0.30 \\
\hline Education (university $=1$ ) & & $(-0.04)$ & $(-0.01)$ & & $(-0.04)$ & $(-0.02)$ \\
\hline Skills $(0-5)$ & & 0.12 & 0.12 & & -0.02 & $(-0.02)$ \\
\hline Risk perception & & 0.17 & 0.14 & & -0.03 & -0.04 \\
\hline $\begin{array}{l}\text { Curvilinearity of risk } \\
\text { perception }\end{array}$ & & 0.08 & 0.07 & & 0.09 & 0.08 \\
\hline $\begin{array}{l}\text { Germany (vs. United } \\
\text { Kingdom) }\end{array}$ & & & 0.13 & & & $(-0.03)$ \\
\hline Spain (vs. United Kingdom) & & & 0.45 & & & $(-0.01)$ \\
\hline $\begin{array}{l}\text { France (vs. United } \\
\text { Kingdom) }\end{array}$ & & & -0.05 & & & 0.24 \\
\hline Italy (vs. United Kingdom) & & & 0.39 & & & $(-0.06)$ \\
\hline $\begin{array}{l}\text { The Netherlands (vs. United } \\
\text { Kingdom) }\end{array}$ & & & -0.20 & & & -0.24 \\
\hline $\begin{array}{l}\text { Poland (vs. United } \\
\text { Kingdom) }\end{array}$ & & & 0.31 & & & $(-0.03)$ \\
\hline $\begin{array}{l}\text { Sweden (vs. United } \\
\text { Kingdom) }\end{array}$ & & & -0.33 & & & -0.42 \\
\hline$R$ squared & 0.08 & 0.14 & 0.22 & 0.49 & 0.51 & 0.53 \\
\hline$F$ & 151 & 104 & 97 & 1,783 & 641 & 388 \\
\hline
\end{tabular}

Notes: Number of respondents $=5,641$ for enabling and 5,633 for restrictive mediation. The numbers in brackets are not statistically significant at the 0.05 level.

child-initiated requests for support in relation to girls, and younger, less skilled children. Mothers restrict more than fathers, as do more digitally skilled parents and older parents. Country differences are less prominent for restrictive mediation than for enabling mediation — though still statistically significant - with more restrictions in France, and fewer restrictions and more child-initiated support in the Netherlands and Sweden.

Perhaps surprisingly, parents who judge risks to be higher are no more likely to implement restrictions; quite the contrary. We therefore tested for a curvilinear relation, finding that a positive curvilinear relation with both enabling $(r=0.07)$ and restrictive mediation $(r=0.08)$. Thus, as parental risk perception rises, parents do more enabling but less restrictive mediation, perhaps following advice that it is better 


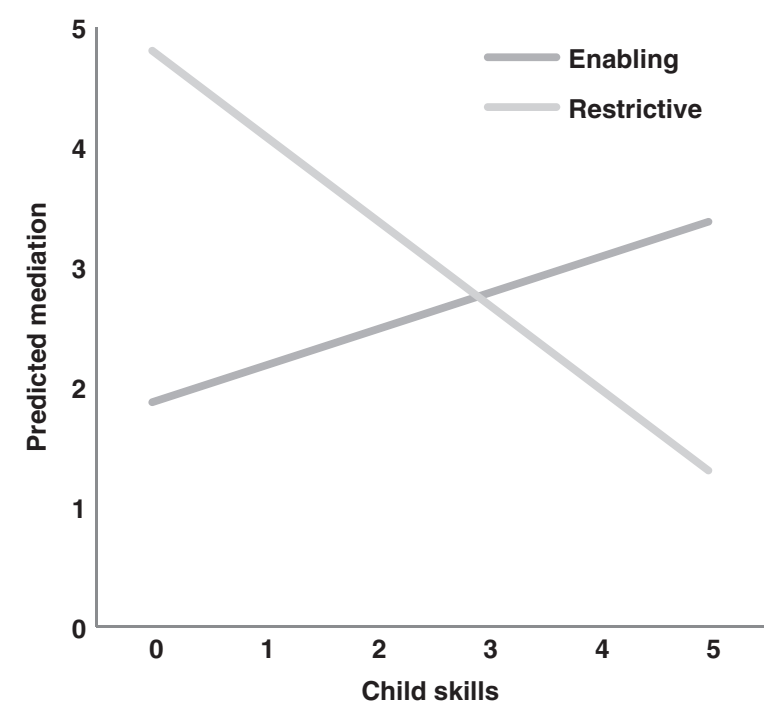

Figure 1 Predicted enabling and restrictive mediation, by child's digital skills.

to get involved in their child's Internet use if they are worried. But as parental risk perception rises yet higher, parents intensify both enabling and restrictive mediation, perhaps believing that enabling alone is insufficient.

Note that parental education makes little difference, whether measured as a binary variable or as the original eight-category scale. Nor is parental education $(r=0.005)$ or parental age $(r=0.01)$ correlated with parents' digital skills, belying the assumption that more educated and/or younger parents are more digitally skilled.

To visualize the results, we present four figures. First, to explore the importance of child skills, Figure 1 shows how parental mediation varies as their report of their child's digital skills rises from 0 to 5 , holding all other variables constant (thus parent skills are fixed at the average, child at age 11, and the prediction is for girls, parents with a university degree, and mothers responding). This shows that for less digitally skilled children, parents choose restrictive mediation but the balance shifts towards enabling mediation as children gain skills.

To explore the effect of parent skills, Figure 2 shows how predicted parental mediation scores change as parental digital skills rise from 0 to 5 , holding all other variables constant (thus, child skills are fixed at the average, age 11, and the prediction is for girls, parents with a university degree, and mothers responding). As this makes clear, the more parents have digital skills, the more they come to prefer enabling over restrictive strategies.

To explore the effect of parental risk perception, Figure 3 shows how predicted parental mediation scores change as parental risk perception increases (holding all other variables constant - child skills are fixed at the average, age 11, and the prediction is for girls, parents with a university degree, and mothers responding). As may be seen, parental risk perceptions do more to increase enabling than restrictive 


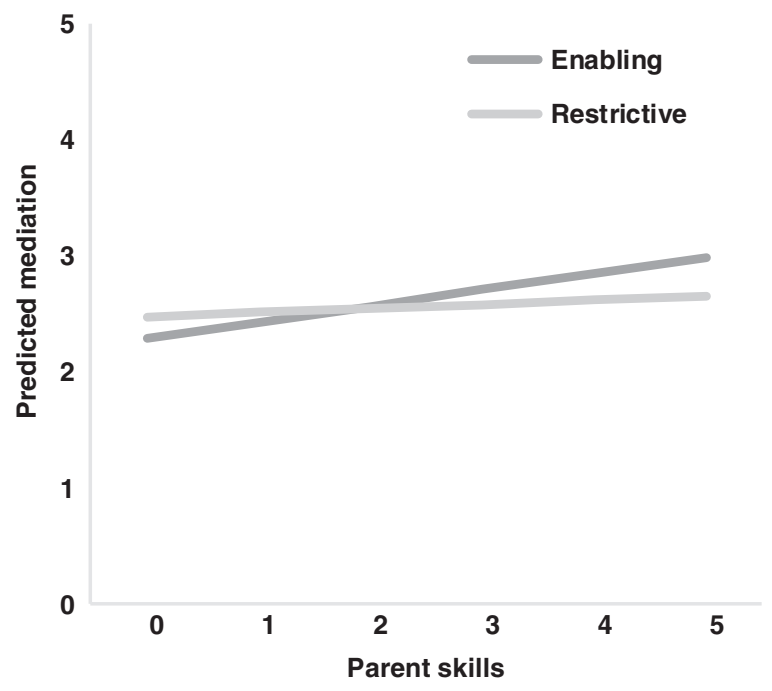

Figure 2 Predicted enabling and restrictive mediation, by parent's digital skills.

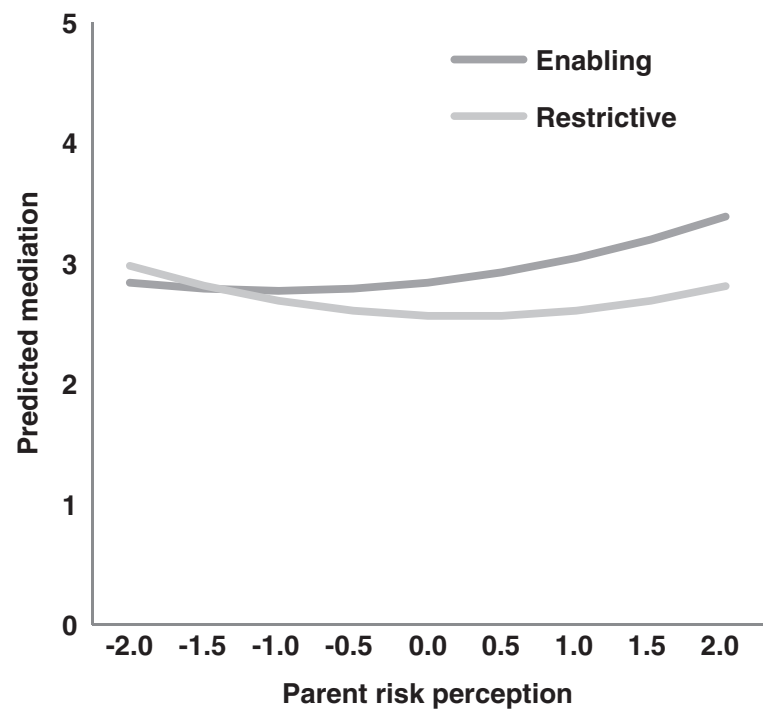

Figure 3 Predicted enabling and restrictive mediation, by parent's risk perception.

mediation, though they have a positive - though markedly curvilinear-effect on both.

Fourth, since the data came from a European study, we also examined country differences (see Helsper, Kalmus, Hasebrink, Sagvari, \& de Haan, 2013). Figure 4 shows average scores for enabling and restrictive mediation for the eight countries included in the survey. This reveals that Spanish and Italian parents combine enabling 


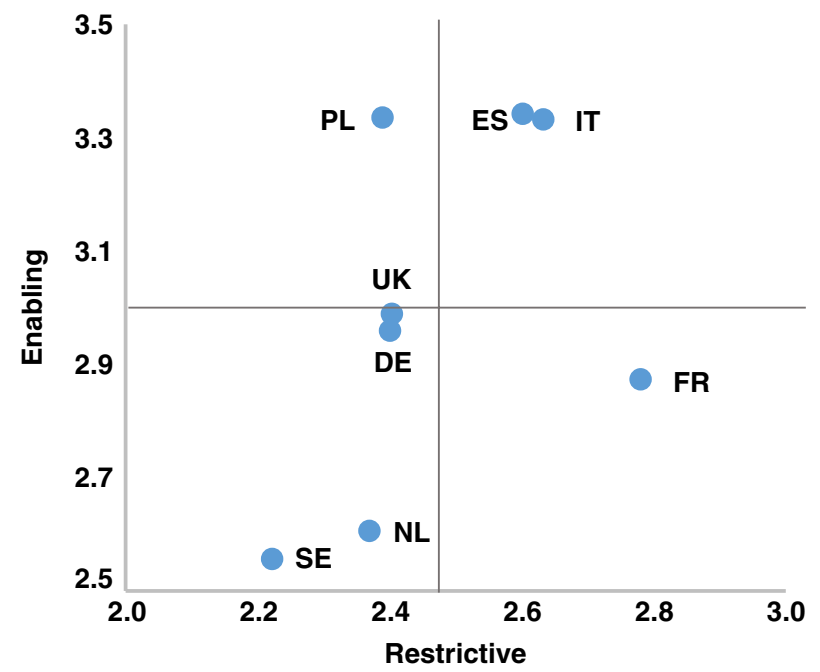

Figure 4 Average enabling and restrictive parental mediation, by country. Note: France (FR), Germany (DE), Italy (IT), the Netherlands (NL), Poland (PL), Sweden (SE), Spain (ES), United Kingdom (UK).

and restrictive strategies, Polish parents tend to favor enabling mediation, French parents favor restrictive mediation, and Swedish and Dutch parents do the least of each strategy, leaving British and German parents somewhere in the middle. A one-way between-groups multivariate analysis of variance (MANOVA) was performed to investigate country differences in parental mediation scores. Enabling and restrictive mediation were entered as dependent variables with country as the independent variable. The result was that there is a statistically significant difference between countries on the combined dependent variables, $F(14,12710)=55.5 ; p<0.001$; Wilk's Lambda $=0.89$; partial eta squared $=0.06$. Of all pairwise country differences, three-quarters for enabling and half for restrictive were significant at $p<0.5$.

\section{RQ3: What are the consequences of parental mediation strategies in balancing children's online opportunities and risks?}

In a cross-sectional survey, especially one based on parental perceptions rather than direct child reports of online opportunities and risks, it is difficult to confidently examine the consequences of parental mediation strategies. However, since we have measures of the child's activities (number of online activities out of 17) and online risks (number of risks encountered out of 10), we conducted two linear regressions to reveal possible patterns that could be worthy of future research. To facilitate comparison between effects on risks and opportunities, both dependent variables were standardized. Table 5 shows two regression models examining the effect of different parenting styles. The regression models were more successful in explaining the variance for opportunities than risks. 
Table 5 Linear Regression Models Showing the Standardized Slope Coefficients for Child's Online Opportunities and Risks

\begin{tabular}{|c|c|c|c|c|c|c|c|c|}
\hline \multirow[b]{2}{*}{ (Constant) } & \multicolumn{4}{|c|}{ Opportunities ( $z$-scores) } & \multicolumn{4}{|c|}{ Risks ( $z$-scores) } \\
\hline & -0.93 & -1.02 & 0.25 & -0.49 & -1.02 & -1.10 & -0.46 & -1.01 \\
\hline Model & I & II & III & IV & I & II & III & IV \\
\hline Age & 0.07 & 0.07 & 0.03 & 0.04 & 0.01 & 0.02 & $(-0.01)$ & $(0.00)$ \\
\hline Gender (girls $=1$ ) & -0.10 & -0.09 & -0.07 & -0.06 & -0.07 & -0.07 & -0.05 & $(-0.05)$ \\
\hline Skills $(0-5)$ & 0.51 & 0.51 & 0.18 & 0.19 & 0.22 & 0.22 & $(0.01)$ & $(0.02)$ \\
\hline Age of parent & -0.02 & -0.02 & -0.02 & -0.01 & -0.02 & -0.02 & -0.01 & -0.01 \\
\hline Gender $($ mothers $=1)$ & -0.25 & -0.25 & -0.16 & -0.15 & -0.19 & -0.19 & -0.14 & -0.13 \\
\hline $\begin{array}{l}\text { Education } \\
\quad(\text { university }=1)\end{array}$ & 0.14 & 0.14 & 0.14 & 0.13 & 0.19 & 0.18 & 0.17 & 0.17 \\
\hline Skills $(0-5)$ & -0.13 & -0.13 & -0.15 & -0.15 & 0.10 & 0.10 & 0.08 & 0.09 \\
\hline Risk perception & 0.07 & 0.06 & $(0.02)$ & 0.02 & 0.22 & 0.22 & 0.19 & 0.19 \\
\hline $\begin{array}{l}\text { Germany (vs. United } \\
\text { Kingdom) }\end{array}$ & & $(-0.01)$ & $(-0.05)$ & $(-0.06)$ & & $(0.05)$ & $(0.02)$ & $(0.01$ \\
\hline $\begin{array}{l}\text { Spain (vs. United } \\
\text { Kingdom) }\end{array}$ & & 0.16 & $(0.06)$ & $(0.05)$ & & $(0.05)$ & $(-0.04)$ & $(-0.04)$ \\
\hline $\begin{array}{l}\text { France (vs. United } \\
\text { Kingdom) }\end{array}$ & & $(0.03)$ & 0.11 & 0.08 & & $(-0.02)$ & $(0.02)$ & $(0.00$ \\
\hline $\begin{array}{l}\text { Italy (vs. United } \\
\text { Kingdom) }\end{array}$ & & 0.19 & 0.12 & 0.11 & & $(0.02)$ & $(-0.05)$ & $(-0.05)$ \\
\hline $\begin{array}{l}\text { The Netherlands (vs. } \\
\text { United Kingdom) }\end{array}$ & & $(0.03)$ & $(-0.01)$ & $(-0.01)$ & & 0.31 & 0.30 & 0.29 \\
\hline $\begin{array}{l}\text { Poland (vs. United } \\
\text { Kingdom) }\end{array}$ & & 0.14 & $(0.06)$ & $(0.07)$ & & 0.18 & 0.12 & 0.12 \\
\hline $\begin{array}{l}\text { Sweden (vs. United } \\
\text { Kingdom) }\end{array}$ & & 0.15 & 0.08 & 0.08 & & 0.14 & 0.12 & 0.12 \\
\hline Enabling mediation & & & 0.25 & 0.48 & & & 0.20 & 0.38 \\
\hline Restrictive mediation & & & -0.36 & -0.08 & & & -0.21 & $(0.01)$ \\
\hline Enabling $\times$ Restrictive & & & & -0.10 & & & & -0.08 \\
\hline$R$ squared & 0.36 & 0.37 & 0.50 & 0.52 & 0.13 & 0.14 & 0.20 & 0.21 \\
\hline$F$ & 397 & 217 & 335 & 339 & 107 & 62 & 82 & 82 \\
\hline
\end{tabular}

Notes: The opportunities and risks scores were standardized as they were measured on different scales (more opportunities asked about than risks).

The analysis shows that older children, more digitally skilled children, and boys take up more online opportunities. More opportunities for children are also reported by parents who are younger, fathers, less skilled, and more educated. Last, more opportunities are reported by parents from Spain, Italy, Poland, and Sweden.

As for online risks, boys and more skilled children encounter these more often, as do (or so they - and their fathers - perceive) those with younger, more skilled, and more educated parents. Parents from the Netherlands, Poland, and Sweden report more risks. 
Table 6 Predicted Outcome (based on multiple regression in Table 5) for Opportunities and Risks (standardized scores) by Parental Mediation

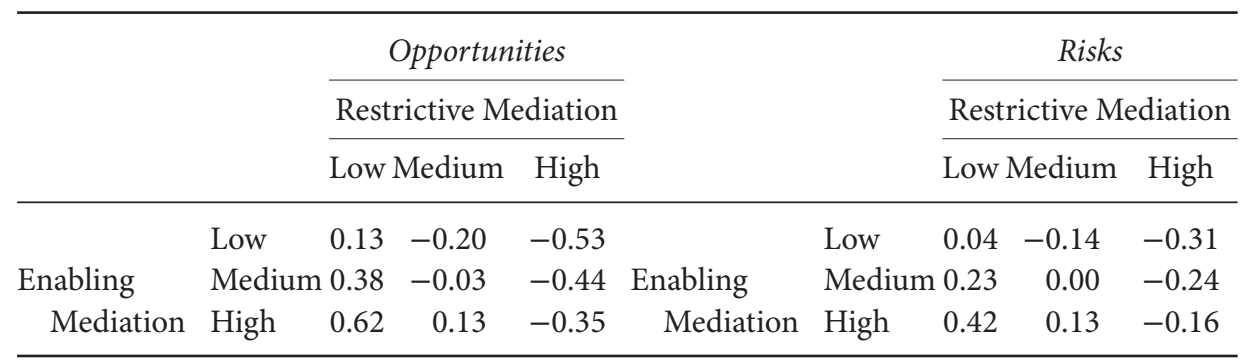

Note: Low, medium, and high levels of mediation are defined as the 25th, 50th, and 75th percentile.

Parental risk perception is positively associated with children's greater online opportunities and risks. It is not possible to determine causality here, but it seems likely that parents more sensitive to or concerned about risk may also be aware of their child's online activities of all kinds. ${ }^{7}$

Parental mediation strategies added considerably to the variance explained in both models: The more parents undertake enabling mediation, the more opportunities and also the more risks their child encounters on the Internet; however, the more restrictive mediation by parents, the fewer risks and opportunities their child encounters.

We then entered the interaction term between parental mediation strategies, which added significantly to the regression analysis (Table 5). To illustrate this finding, Table 6 compares predicted outcomes in terms of online opportunity and risk for the different combinations of enabling and restrictive mediation. This shows that enabling mediation produces a differentially larger increase in opportunities when restrictions are low than when they are high, while restrictive mediation produces a differentially larger decrease in risks when enabling is high.

Our study found no combination of enabling and restrictive mediation that both increases opportunities and reduces risks. As Table 6 shows, if parents choose a low level of both restrictive and enabling mediation, this is predicted to increase opportunities by a 0.13 standard deviation and to increase risks by a 0.04 standard deviation. The combination of high enabling and medium restrictive mediation results in a 0.13 increase in both opportunities and risks. The maximum increase in opportunities is predicted by choosing high enabling and low restrictive mediation, resulting in a 0.62 increase in opportunities but also a 0.42 increase in risks. The maximum decrease in risks can be achieved by choosing high restrictions but that will also result in the greatest reduction in opportunities.

\section{Discussion}

Much previous research has examined parental efforts to restrict their children's media use so as to minimize their exposure to risks, leaving it unclear how parents can 
support children's online opportunities. Our survey suggests that parents are now finding ways to mediate their child's Internet use differently from television viewing, and that the initial array of strategies identified by research is resolving into two broad strategies - enabling and restrictive (as asked by RQ1). Enabling mediation is more complex than the 'active' mediation found for television viewing, reflecting the greater complexity of supporting children's Internet use. It encompasses "active" mediation along with safety mediation and activities that might seem restrictive (use of technical controls and parental monitoring) but are better interpreted as building a safe framework precisely so that children's positive uses of the Internet can be encouraged.

Enabling mediation enables not only children's Internet use but also children's agency within the parent-child interaction, as shown by the positive association with child-initiated requests for parental support. Many parents also take a restrictive approach to Internet use, as for television, but restrictive mediation is negatively associated with child-initiated support, suggesting that parental restrictions discourage children's agency and may even create a negative dynamic whereby children with restrictive parents learn not to draw parental attention to their Internet use. Our empowered-but-safe interpretation of enabling mediation explains why enabling mediation increases, rather than decreases, the more parents judge the Internet to be risky. Restrictive mediation comes into play when risk perception is particularly high, even though the cost is that children reduce requests to parents to support their Internet use, possibly leaving parents less informed about or able to guide their child.

For television viewing, the relation between active and restrictive mediation was sometimes interpreted as presenting opposite strategies between which parents should choose (Blum-Ross \& Livingstone, 2016). The present survey suggests that, for Internet use, enabling and restrictive strategies are independent: Thus parents choose either or both, in various measures. This independence invites parallels between parental mediation and Baumrind's (1991) work on how adolescents become self-regulating as a result of parental styles varying in warmth (or responsiveness) and control (or demandingness), as explored in relation to "Internet parenting styles" (Valcke et al., 2010; also Eastin et al., 2006; Nakayama, 2011; Valkenburg et al., 2013). From Baumrind's two dimensions, four styles have been identified: authoritative (parents are more responsive and demanding than average), authoritarian (characterized by high control but low warmth), permissive (warm and supportive but nondemanding), and laissez-faire parenting (or neglectful or uninvolved parenting, which is low in demands and responsiveness). Applying Baumrind's parental styles to the Internet, Valcke et al. found that authoritative parents often combine mediation strategies while others tend to select among the strategies, with authoritarian parents favoring Internet restrictions and permissive parents favoring active mediation.

Although due to limitations of space our survey did not include measures of parental style, inclusion of other parent and child variables allowed us to frame RQ2 to ask what influences the balance parents strike between enabling and restrictive mediation. Consistent with previous literature, we found that younger children receive more parental mediation and that girls receive more restrictive mediation 
in particular. Importantly, our use of a comprehensive measure of digital skills was successful in revealing the decisive role of the digital skills of both parents and children. First, parents are more restrictive if they judge themselves less skilled. Conversely, the better the parental skills, as assessed by parents themselves, the more they prefer enabling mediation. This suggests that enabling mediation is more demanding as a strategy, or that more skilled parents are more aware of the online opportunities available and so choose not to restrict their child. Second, parents favor restrictive mediation when they judge their child to be lower on digital skills, turning to enabling mediation the more they judge their child to be digitally skilled. Thus parents respond to their child's Internet competence and experience, preferring a risk-averse restrictive strategy for less skilled children but encouraging and supporting children if they are, or as they become, more competent Internet users.

Parental strategies are also shaped by culture, as measured here through cross-national comparisons. Swedish and Dutch parents, found to do the least parental mediation, were interestingly found by O'Neill's (2014) comparison of policy frameworks and actions to have implemented the most rigorous frameworks at the national level, suggesting a trade-off is reached at the national level between top-down regulation and parental mediation. Relatedly, Italian parents are high on both enabling and restrictive mediation, while their national policy implementation ranks among the lowest in O'Neill's European comparisons. It is harder to match parental mediation and policy implementation for the other countries - Polish parents favor enabling and French parents restrictive mediation, for instance, although both countries are below average in policy implementation, according to O'Neill's analysis, while Germany, Spain, and the United Kingdom are strong on both policy and parental mediation. If we reinterpret the quadrants in Figure 4 as authoritative (high on enabling and restrictive mediation), authoritarian (low on enabling and high on restrictive), permissive (high on enabling and low on restrictive), and laissez-faire (low on enabling and restrictive mediation), this invites future research on country-specific factors, including values relating to child-rearing and risk (Helsper et al., 2013; Kirwil, 2009). Here it should be borne in mind that in predicting parental mediation, country mattered more when explaining variation in enabling than restrictive mediation.

To explore the consequences of parental mediation in relation to not only risks but also opportunities (RQ3), we examined the relation between parental mediation strategies and the reported consequences of children's Internet use. Notably, the findings did not reveal the hoped-for strategy that could simultaneously maximize opportunities and minimize risks. Rather, they pinpointed the complex choice that parents face: More enabling mediation was positively associated with children's online opportunities and so is likely to optimize them but also to increase risks; more restrictive mediation was associated with fewer risks but also with fewer opportunities. This makes problematic the tendency of policy makers concerned with risk to urge parents to restrict children's Internet use without recognizing the costs to their online opportunities, as well as the tendency of educators to urge 
parents to enable children's Internet use without recognizing that this may bring more risk (O’Neill et al., 2013).

To escape the costs of either approach, the present findings regarding digital skills suggest a promising direction. Enabling mediation is practiced more by parents who judge their own or their children's digital skills to be relatively high, but are also aware of the risks of Internet use. So even though the outcome is more online risk as well as more opportunities, such parents may be confident that they and their children can deal with risk when it occurs, thereby avoiding or minimizing actual harm (Livingstone, 2013). Conversely, parents are more restrictive when they doubt their own or their children's digital skills to deal with risk, or because they perceive the risk of harm to be very high; such circumstances may be due to vulnerabilities affecting the child that were beyond the scope of this study to measure. Under such circumstances, it may be reasonable to minimize risks, even at the cost of opportunities.

However, the importance of digital skills in parental mediation could compound the very inequalities that surely explain observed differences in parent or child digital skills. For in restricting their child's Internet use, parents who are more fearful or less skilled (or whose child is less skilled) reduce both the child's online opportunities and, by reducing exposure to adversity, their chance to develop resilience (Coleman \& Hagell, 2007). Meanwhile, it is likely that more skilled children and parents are more free to explore and benefit from online opportunities while also building up resilience against harm by meeting a degree of online risk. We therefore recommend not only that digital skills are attended to in future research on parental mediation but also that parental mediation is attended to in future research on digital inclusion and exclusion (van Dijk \& van Deursen, 2014). Furthermore, policies to remedy children's digital exclusion should work to support both their own and their parents' digital skills. In terms of guidance and awareness-materials targeting parents, these should differentiate among parents (and children) according to their digital skills, recognizing that not all parents are less skilled than their children, and that parents may wish to enable their child's Internet use along with positive child-parent interactions around digital media, rather than simply seek to control and restrict their media activities (Blum-Ross \& Livingstone, 2016; Clark, 2011). Specifically, future advice to parents should encourage them to develop their digital skills and those of their child, and reflect on how these can enhance online opportunities and build resilience through coping with adversity as it arises.

The findings offer little justification for recommending authoritative mediation to parents, as discussed in relation to Table 6, even though recent research and policy has tended to urge that parents combine enabling and restrictive mediation (Blum-Ross \& Livingstone, 2016; Chassiakos et al., 2016). Rather than supporting Valkenburg et al.'s (2013) hope that such a combination could simultaneously stimulate the child's autonomy while also restricting risky activities, it may be that Nikken and Schols (2015) are right that, as their longitudinal panel research revealed, the combination of enabling and restrictive mediation appears inconsistent to the child, possibly making them anxious about exploring opportunities while leaving openings for risk, or 
confusing them by seeming to invite child-initiated requests for support but then confounding children when parents respond with restrictions. Again the value of considering the child's perspective on parental mediation is important, possibly holding the key to a strategy that does not leave parents facing the choice between maximizing opportunities while increasing risk or reducing risk at the cost of opportunities.

The present study has a number of strengths and limitations. It built on the tried-and-tested measures developed by EU Kids Online, while also improving on that study's measures of digital skills and extending the examined range of risks. Having conducted the study in eight different countries with over 6,000 respondents, it was also possible to compare differences in parental mediation between countries. Nevertheless, the study has some limitations. Since the study is based on a cross-sectional survey, the effects of parental mediation can only be inferred from observed correlations with risks and opportunities. Moreover, it was administered only to parents, and it would be valuable also to investigate children's accounts of the effects of different parental mediation strategies on their online experiences. Had there been more time within the survey, it would have been useful to add general measures of parental style or family communication, to see if these explain the observed combinations of parental mediation strategies, possibly linking these to parental values or cultural values in different countries and, thereby, to the development of more targeted and nuanced parenting advice.

\section{Conclusions}

Following the rapid adoption of the internet and related digital media in homes and schools, this article has argued that it is time for researchers, policy makers, and parents to rethink the dominant emphasis on harm in parental mediation research and parenting advice. We have found that many parents are skilled in using the Internet and use their skills to support their child's emerging digital skills and interests in ways that are responsive to children's needs and build safety considerations into an overall enabling strategy. Those who are less confident of their own or their child's digital skills take a more restrictive approach but could, in future, be encouraged to develop their skills so as to enable their child's online opportunities and cope with risks. Indeed, by recognizing the challenge facing parents in a heavily mediated age - simultaneously to maximize online opportunities and minimize risks - we have proposed that policies to improve digital skills for both parents and children could provide a valuable lever in effecting change. Since this has been shown to support enabling mediation and, thereby, bring more online opportunities for children even at the cost of risks, this should clearly be combined with efforts to enhance children's and parents' coping strategies and resilience in the face of risk, so that it does not lead to actual harm.

\section{Acknowledgments}

This study has been funded under the Request for Specific Services EAHC/FWC/ 20138508 for the implementation of the Framework contract EAHC/2011/CP/01/LSE 
for the provision of a "Study on the impact of marketing through social media, online games and mobile applications on children's behaviour" available at http://ec .europa.eu/consumers/consumer_evidence/behavioural_research/impact_media_ marketing_study/index_en.htm. It was produced under the Consumer Programme (2007-2013) in the frame of a contract with the Consumer, Health, Agriculture and Food Executive Agency (CHAFEA) acting on behalf of the European Commission. The content of this study represents the views of London School of Economics and Political Science and is its sole responsibility; it can in no way be taken to reflect the views of the European Commission and/or CHAFEA or any other body of the European Union. The European Commission and/or CHAFEA do not guarantee the accuracy of the data included in this report, nor do they accept responsibility for any use made by third parties thereof. Thanks to Leslie Haddon, Tijana Milosevic, and Elisabeth Staksrud for comments on an earlier version of this article.

\section{Notes}

1 The adaptation was to shorten the scales (selecting items according to those that loaded most strongly on the original factor analysis used in the scale production) and to rephrase some items to ease translation and ensure its reliability across the eight languages of the study. These changes were made in consultation with the scale producers.

2 One mobile item was omitted as not relevant to parents.

3 For binary variables the coefficient is also known as KR20, so alpha is used here as a generic term.

4 The coefficient could not be improved by omitting any of the items, and may also be lower than others because of the use of binary response options (Sijtsma, 2009).

5 This is confirmed by Bartlett's Test of Sphericity, which was significant (i.e., the null hypothesis of independence in the correlation matrix was rejected; $\mathrm{X}^{2}=\operatorname{Inf}, d f=15$, $p<2.22 \mathrm{e}-16)$.

6 To check on the analysis we also conducted a factor analysis using the separate items across the six scales for parental mediation. This replicated the two-factor solution reasonably well. But since the response items differed for each scale, we decided first to harmonize the scoring and then conduct the factor analysis on the six scales. We also repeated the factor analysis using an oblique rotation (direct oblimin and promax), finding that this resulted in a low correlation between the factors $(-0.09$ and -0.04$)$. Thus we concluded that the best-fit factors are orthogonal.

7 Note that adding the curvilinearity of parental risk perception did not alter the equation, being nonsignificant. The curvilinearity effect was therefore excluded from the model.

\section{References}

Baumrind, D. (1991). The influence of parenting style on adolescent competence and substance use. Journal of Early Adolescence, 11(1), 56-95.

Beck, U. (1992). Risk society: Towards a new modernity. London, England: SAGE.

Blum-Ross, A., \& Livingstone, S. (2016). Families and screen time: Current advice and emerging research. London, England: LSE Media Policy Project.

Chang, F. C., Chiu, C. H., Miao, N. F., Chen, P. H., Lee, C. M., Chiang, J. T., \& Pan, Y. C. (2015). The relationship between parental mediation and Internet addiction among 
adolescents, and the association with cyberbullying and depression. Comprehensive Psychiatry, 57, 21 -28. doi:10.1016/j.comppsych.2014.11.013.

Chassiakos, R. Y. L., Radesky, J., Christakis, D., Moreno, M. A., \& Cross, C. (2016). Children and adolescents and digital media. Pediatrics, 138, 5. doi:10.1542/peds.2016-2593.

Clark, L. S. (2011). Parental mediation theory for the digital age. Communication Theory, 21(4), 323-343.

Coleman, J., \& Hagell, A. (Eds.) (2007). Adolescence, risk and resilience: Against the odds. Chichester, England: Wiley.

Connell, S. L., Lauricella, A. R., \& Wartella, E. (2015). Parental co-use of media technology with their young children in the USA. Journal of Children and Media, 9(1), 5-21. doi:10.1080/17482798.2015.997440.

Dürager, A., \& Sonck, N. (2014). Testing the reliability of scales on parental Internet mediation. London, England: EU Kids Online, LSE.

Eastin, M., Greenberg, B., \& Hofschire, L. (2006). Parenting the Internet. Journal of Communication, 56, 486-504.

European Society for Opinion and Marketing Research (2015). Global guideline: Online research. Amsterdam, the Netherlands: ESOMAR.

Garmendia, M., Garitaonandia, C., Martinez, G., \& Casado, M. Á. (2012). The effectiveness of parental mediation. In S. Livingstone, L. Haddon, \& A. Görzig (Eds.), Children, risk and safety on the Internet (pp. 231-244). Bristol, England: Policy Press.

Giddens, A. (1991). Modernity and self identity: Self and society in the late modern age. Cambridge, England: Polity.

Guernsey, L., Levine, M., Chiong, C., \& Severns, M. (2014). Pioneering literacy in the digital Wild West. New York, NY: Joan Ganz Cooney Center at Sesame Workshop.

Hargittai, E. (2002). Second-level digital divide: Differences in people's online skills. First Monday, 7, 4. Online.

Helsper, E. J. (2012). A corresponding fields model of digital inclusion. Communication Theory, 22(4), 403 -426. doi:10.1111/j.1468-2885.2012.01416.x.

Helsper, E. J., Kalmus, V., Hasebrink, U., Sagvari, B., \& de Haan, J. (2013). Country classification: Opportunities, risks, harm and parental mediation. London, England: EU Kids Online, LSE.

Jessop, B. (2000). The state and the contradictions of the knowledge-driven economy. In J. R. Bryson, P. W. Daniels, N. D. Henry, \& J. Pollard (Eds.), Knowledge, space, economy (pp. 63-78). London, England: Routledge.

Khurana, A., Bleakley, A., Jordan, A. B., \& Romer, D. (2015). The protective effects of parental monitoring and Internet restriction on adolescents' risk of online harassment. Journal of Youth and Adolescence, 44(5), 1039-1047. doi:10.1007/s10964-014-0242-4.

Kirwil, L. (2009). Parental mediation of children's Internet use in different European countries. Journal of Children and Media, 3(4), 394-409.

Lau, W. W. F., \& Yuen, A. H. K. (2013). Adolescents' risky online behaviours: The influence of gender, religion, and parenting style. Computers in Human Behavior, 29(6), 2690-2696. doi:10.1016/j.chb.2013.07.005.

Leung, L., \& Lee, P. S. N. (2012). The influences of information literacy, Internet addiction and parenting styles on Internet risks. New Media \& Society, 14, 137-151.

Litt, E. (2013). Measuring users' Internet skills: A review of past assessments and a look toward the future. New Media \& Society, 15(4), 612 -630. doi:10.1177/1461444813475424. 
Livingstone, S. (2013). Online risk, harm and vulnerability: Reflections on the evidence base for child Internet safety policy. ZER: Journal of Communication Studies, 18, 13-28.

Livingstone, S., Haddon, L., Görzig, A., \& Ólafsson, K. (2011). Risks and safety on the Internet: The perspective of European children. EU Kids Online, LSE: Full findings. London, England.

Livingstone, S., \& Helsper, E. J. (2008). Parental mediation of children's Internet use. Journal of Broadcasting \& Electronic Media, 52(4), 581-599.

Lupiáñez-Villanueva, F., Gaskell, G., Veltri, G., Theben, A., Folkford, F., Bonatti, L., ... , Codagnone, C. (2016). Study on the impact of marketing through social media, online games and mobile applications on children's behaviour. Luxembourg, Luxembourg: Publications Office of the European Union. Retrieved from the European Commission. http://ec.europa.eu/consumers/consumer_evidence/behavioural_research/docs/final_ report_impact_marketing_children_final_version_approved_en.pdf (27 November 2016)

Mascheroni, G., Murru, M. F., Aristodemou, E., \& Laouris, Y. (2013). Parents. Mediation, self-regulation and co-regulation. In B. O’Neill, E. Staksrud, \& S. McLaughlin (Eds.), Towards a better Internet for children? (pp. 211-225). Göteborg, Sweden: Nordicom.

McDevitt, M., \& Chaffee, S. (2002). From top-down to trickle-up influence: Revisiting assumptions about the family in political socialization. Political Communication, 19(3), 281-301. doi:10.1080/01957470290055501.

Mesch, G. S. (2009). Parental mediation, online activities, and cyberbullying. CyberPsychology \& Behavior, 12(4), 387-393.

Nakayama, M. (2011). Parenting style and parental monitoring with information communication technology: A study on Japanese junior high school students and their parents. Computers in Human Behavior, 27, 1800-1805.

Nathanson, A. I. (1999). Identifying and explaining the relationship between parental mediation and children's aggression. Communication Research, 26(2), 124-143.

Nathanson, A. I. (2015). Media and the family: Reflections and future directions. Journal of Children and Media, 9(1), 133-139. doi:10.1080/17482798.2015.997145.

Nikken, P., \& Schols, M. (2015). How and why parents guide the media use of young children. Journal of Child and Family Studies, 24(11), 3423-3435. doi:10.1007/s10826-015-0144-4.

O'Neill, B. (2014). Policy influences and country clusters: A comparative analysis of Internet safety policy implementation. London, England: EU Kids Online, LSE.

O’Neill, B., Staksrud, E., \& McLaughlin, S. (Eds.) (2013). Children and Internet safety in Europe: Policy debates and challenges. Göteborg, Sweden: Nordicom.

Ochs, E., \& Kemer-Sadlik, T. (Eds.) (2013). Fast-forward family: Home, work, and relationships in middle-class America. Berkeley/Los Angeles: University of California Press.

Ofcom (2016). Adults' media use and attitudes report. London, England: Office of Communications.

Pasquier, D., Simões, J. A., \& Kredens, E. (2012). Agents of mediation and sources of safety awareness: A comparative overview. In S. Livingstone, L. Haddon, \& A. Görzig (Eds.), Children, risk and safety on the Internet (pp. 219-230). Bristol, England: Policy Press.

Rosen, L. D., \& Kostjukovsky, I. (2015). Parental risk perceptions of child exposure to tobacco smoke. BMC Public Health, 2, 3. doi:10.1186/s12889-015-1434-x.

Rosen, L. D., Cheever, N. A., \& Carrier, L. M. (2008). The association of parenting style and child age with parental limit setting and adolescent MySpace behavior. Journal of Applied Developmental Psychology, 29(6), 459-471. 
Rudi, J. H., Walkner, A., \& Dworkin, J. (2014). Adolescent-parent communication in a digital world: Differences by family communication patterns. Youth \& Society, 47(6), 811-828. doi:10.1177/0044118x14560334.

Shin, W. (2013). Parental socialization of children's Internet use: A qualitative approach. New Media \& Society, 17(5), 649-665. doi:10.1177/1461444813516833.

Shin, W., \& Huh, J. (2011, June). Children's online privacy risks and the role of parental mediation. Paper presented at the AMA Marketing and Public Policy Conference, Washington DC.

Sijtsma, K. (2009). On the use, the misuse, and the very limited usefulness of Cronbach's alpha. Psychometrika, 74(1), 107-120. doi:10.1007/s11336-008-9101-0.

Slovic, P. (2004). Perception of risk. International Library of Critical Writings in Economics, 178, $97-102$.

Spink, A., Danby, S., Mallan, K., \& Butler, C. (2010). Exploring young children's web searching and technoliteracy. Journal of Documentation, 66(2), 191-206.

Staksrud, E. (2013). Children in the online world: Risk, regulation, rights. Aldershot, England: Ashgate.

Troseth, G. L., Russo, C. E., \& Strouse, G. A. (2016). What's next for research on young children's interactive media? Journal of Children and Media, 10, 54-62.

UNESCO (2006). International Standard Classification of Education ISCED 1997, Re-edition. Paris, France: United Nations Educational, Scientific and Cultural Organization.

Vaala, S. E., \& Bleakley, A. (2015). Monitoring, mediating, and modeling: Parental influence on adolescent computer and Internet use in the United States. Journal of Children and Media, 9(1), 40-57. doi:10.1080/17482798.2015.997103.

Valcke, M., Bonte, S., de Wever, B., \& Rots, I. (2010). Internet parenting styles and the impact on Internet use of primary school children. Computers \& Education, 55(2), 454-464.

Valkenburg, P. M., Krcmar, M., Peeters, A. L., \& Marseille, N. M. (1999). Developing a scale to assess three different styles of television mediation: 'Instructive mediation', 'restrictive mediation', and 'social coviewing'. Journal of Broadcasting and Electronic Media, 43(1), $52-66$.

Valkenburg, P. M., Piotrowski, J. T., Hermanns, J., \& de Leeuw, R. (2013). Development and validation of the perceived parental mediation scale: A self-determination perspective. Human Communication Research, 39(4), 445-469.

van den Bulck, J., Custers, K., \& Nelissen, S. (2016). The child-effect in the new media environment: Challenges and opportunities for communication research. Journal of Children and Media, 10(1), 30-38.

van Deursen, A. J. A. M., Helsper, E. J., \& Eynon, R. (2015). Development and validation of the Internet skills scale (ISS). Information, Communication \& Society, 19(6), 804-823. doi:10.1080/1369118X.2015.1078834.

van Dijk, J. A. G. M., \& van Deursen, A. J. A. M. (2014). Digital skills, unlocking the information society. Palgrave Macmillan.

Wartella, E., Beaudoin-Ryan, L., Blackwell, C. K., Cingel, D. P., Hurwitz, L. B., \& Lauricella, A. R. (2016). What kind of adults will our children become? The impact of growing up in a media-saturated world. Journal of Children and Media, 10, 13-20. 